\title{
Energy Policy
}

\section{Special issue on European Union: Markets and Regulators Editorial}

Costa-Campi, M. T.

Giulietti, M.

Trujillo-Baute, E.

\begin{abstract}
The European Union has taken a leading role in the process of transformation of the energy sector for the transition to a low carbon economy. This has created several opportunities and challenges for policymakers and businesses operating in the energy sector as new directives and regulations are developed and implemented. To improve our understanding on the nature of these emerging challenges a workshop was organised in Barcelona on February $3^{\text {rd }}$ 2015, which saw the participation of eminent energy researchers from across the European academia. This introduction to the special issues provides some reflection about the challenging issues being tackled by the European Commission and individual Members States. The second section summarises the articles from the workshop, which make up this special issue and which provide insightful evidence, commentary and policy recommendations for a successful and efficient transformation to a low carbon European energy system.
\end{abstract}

\section{Emerging challenges for business and regulators in European energy markets}

Recent developments in global energy markets have generated opportunities and challenges for businesses and policymakers due to the rapid increase in energy demand from emerging and developing countries, geopolitical instability in different parts of the world, and most importantly the growing concerns about the impact of climate change on the quality of human and natural life, leading several countries to engage in decarbonisation policies and actions. The policy makers in the European Union have attempted to tackle such challenges over time through a series of legislative and regulatory interventions in the areas of climate and energy policy.

While the development of the European economic integration has had energy policy as one of its main pillars since its inception in the 1950s, starting from the 1990s energy markets in Europe have been shaped by both national and supra-national (EU) policies simultaneously pursuing the objective of creating an internal energy market subject to competitive forces but with limited coordination across Member States. This has led to the creation of energy only markets with different characteristics and regulatory frameworks across Europe (Marty, 2014). The European Union has for many years played a leading role in the process of 
liberalisation of the energy sector through a series of legislative and regulatory interventions aimed at promoting the creation of an internal energy market through a process of privatisation, liberalisation and integration across national energy markets.

In recent years however, the additional policy objectives of decarbonisation and security of supply have dramatically transformed the energy sector across Europe leading to increased penetration of renewable technologies; a transformation that has created challenges for the different European energy systems, characterised by the presence of energy only markets, as a result of deregulation policies promote by successive EU energy directives. The creation of energy-only markets in Europe can be ascribed at least in part to a general mistrust of long term contracts, due to the potential risk of abuse of market power and market foreclosure which have been associated with them in the academic literature and in the practice of competition policy (see de Hautecloque, 2009 and Motta, 2004). However the recent radical transformations of the European energy system have led to questions about the suitability of energy-only markets to provide reliable and affordable energy in the presence of increasing penetration of generation from intermittent and renewable sources (Henriot et al., 2013). As a result of this transformation the provision of balancing and flexibility services has become increasingly important with significant economic effects on final consumers' energy bills (e.g. see Huber et al., 2014). Furthermore the introduction of carbon prices has altered the fuel mix for electricity generation, indirectly affecting the gas prices observed in European markets, as discussed in some of the contributions to the special issue summarised below.

The pursuit of decarbonisation objectives and the ensuing increased penetration of generation from renewable sources have had important consequences also in terms of the need to extend, reinforce and further integrate the European electricity networks in order to address the increasing needs for flexibility and reserve services. Furthermore, the pursuit of policy objectives of security of supply has become more prevalent in the gas industry in recent years (e.g. see Westphal, 2014). The recent investment in the European gas networks and transportation systems has been dictated by the need to address security of supply problems in gas markets as a precautionary measure against re-emerging geopolitical instability and changes in the trade flows following the Fukushima accident and the boom of shale gas production in the US.

As a consequence of the repositioning of European energy policy which has moved beyond the objectives of liberalisation and market integration towards an extended list of objective, including security of supply and decarbonisation, the implementation of energy policy measures by regulators and businesses has become more complex and challenging, and has led to potential conflicts between objectives, with costly consequences for energy users and taxpayers. The cost effectiveness of decarbonisation and energy policy measures is becoming an increasingly important criterion of policy evaluation as the affordability of energy bills is a prominent thought in the European taxpayers' and voters' minds, while fuel poverty is becoming a 
growing social concern. However the implementation of energy and climate policies has not always been pursued in a cost effective manner, in part as a result of a lack of coordination across different the Member States or due to different authorities devising and implementing policy measures in different climate and energy related sectors.

The workshop on Energy Markets and Sustainability was organised at University of Barcelona with the aim of investigating the challenges facing European countries in their attempts to develop policies which promote the development of efficient, resilient and sustainable energy markets.

\section{Overview of the contributions to the special issue}

The papers in this special issue discuss the complex interaction between industry, markets, regulators and policy makers who are involved in enacting the transition to low carbon energy systems. The electricity sector in particular is facing considerable challenges as the industry where the most intense activity is taking place, with the aim of addressing decarbonisation objectives. This has resulted in sustained technological change and policy interventions in the form of market reform and Government support to emerging renewable technologies.

\subsection{Missing Markets}

Newbery (2016) discusses the role of missing money and missing market problems in relation to the reliability and adequacy issues currently faced in the European energy-only markets. The paper argues that the biases towards over-procurement of capacity in existing capacity mechanisms can exacerbate the missing money problems associated with energy-only markets, partly as a result of ignoring missing market problems, such as the lack of relatively long term future markets. More specifically the paper assesses the outcome of the first capacity auction in the UK and its ability to address the market failures associated with energy-only markets which are becoming prevalent in Europe following the implementation of the Third Energy package.

The author also discusses the relationship between capacity mechanisms and crossborder trading, reaching the conclusion that in order to address the reliability problems associated with the increased penetration of generation from renewable sources, the EU Target Electricity Market (TEM) should be operate on the basis of true scarcity prices, but also rely on bilateral agreements between system operators regarding the actions to be taken at stress events. The market design of the European TEM was based on the set up of the Scandinavian energy-only market Nord Pool, which has not experienced capacity adequacy issues despite the fact that it does not rely on capacity payment mechanisms. In line with this assessment of the main features of European electricity market, the author therefore argues that, in the presence of reliable price signals guiding cross-border trading and in the absence direct policy interventions, the implementation of a common capacity market would 
not be required in order to deal with reliability issues at the European level, so that different Member States would be able to independently develop their own capacity market design, on the basis of the experience of recently developed capacity markets.

\subsection{Empirical Assessment of Market Liberalization and RES integration}

The next three contributions rely on recent empirical evidence and data analysis to assess the impacts of energy market liberalisation and integration of high levels of generation from intermittent renewable sources in electricity systems. Two of these contributions provide estimates of the costs associated with such integration while the third one assesses the balancing costs associated with the introduction of retail market competition.

The role of balancing markets has become increasing critical for the reliability of power systems characterised by high levels of penetration of generation from renewable sources. The contribution Batalla-Bejerano and Trujillo-Baute (2016) attempts to assess the contrasting effects of the increased penetration of renewables on retail electricity pricing. While the cost of subsidizing renewable technologies is reflected directly in final energy bills the low marginal cost of energy from this sources has led to a reduction in wholesale prices. At the same time the volatility and intermittency of supply form renewable sources has caused an increase in the cost of ancillary and balancing services which has contributed to increasing energy bills for final consumers. The authors of this paper contribute to the debate about the implications of increasing renewable penetration by providing empirical evidence about the effect of renewables integration on balancing requirements and costs in the Spanish electricity market. The Spanish case is particularly significant as Spain has levels of installed capacity of renewable energy among the highest in Europe and one of the highest levels of penetration of wind and solar percentage of total energy supply from renewables in the European Union. Furthermore Spain is characteristic by a relatively interconnection with neighbouring countries, which makes the challenges of ensuring a reliable and adequate electricity supply more difficult to meet in the presence of high levels of variable generation from renewable sources. However the authors also point out the effect of increased renewable energy penetration depends on the state of the system so that it would be difficult generalise their impact on the demand for ancillary services across different timescales and systems. The empirical analysis of the recent changes in balancing costs in the Spanish electricity markets leads the authors to conclude that both uncertainty and variability in supply have a positive effect on adjustment costs. They also argue that the availability of flexible plant is more critical in countries with limited interconnection such as Spain in order to limit the adjustment costs associated with intermittent generation. 
Recent changes in balancing requirements which have emerged as a result of regulatory interventions in Spain are also the focus of the contribution by BatallaBejerano, Costa-Campi and Trujillo-Baute (2016), who investigate the impact of the retail market liberalisation in 2009 on the costs of Spanish electricity system and, as a consequence, on final consumers prices. The authors argue that the transposition of the second EU energy directive into national regulation with the objective of promoting competition in the retail market had generated unexpected effects in other parts of the Spanish energy system, causing an increase in balancing costs. By analysing the cost of volume adjustments before and after the 2009 market reform the authors are able to estimate the impact on final consumer bills of the additional costs associated with the balancing requirement induced by deviations of demand from predicted volumes. The authors identify significant changes in the balancing requirements of the Spanish energy system as a result of the transition to a competitive retail market due to the change in the role of the local distribution system operators. The new balancing requirements have arisen from the limited ability of energy suppliers to produce reliable estimates for final demand on the basis of a limited amount of metered data, which makes it more likely that differences between estimated and actual demand will be observed. According to the authors' estimates balancing requirements in the Spanish electricity system saw increases in excess of $30 \%$ in the year after the market reform. This was translated into an increase of around 0.3 euros/MWh in final electricity bills. The authors recognise that widely adopted smart meters would mitigate the balancing requirements associated with deviations of actual from forecast demand, however their main policy recommendation is that these additional balancing costs should be borne by suppliers or by the regulator, rather than by consumers, in order to give suppliers adequate incentives to mitigate the additional flexibility requirements. The general issue of increased balancing requirements arising from market liberalisation discussed in this paper for the Spanish case is not an exception, but rather applies also to other European countries which have developed similar market designs as a result of the transposition of EU energy directives, and so do the policy recommendations proposed by the authors.

The contribution by Gianfreda, Parisio and Pelagatti (2016) on the other hand asks whether the long-run relationship between fossil fuel prices and electricity prices needs to be revisited as a result of the effect of increased penetration of generation from renewable sources and increased integration of energy markets in the European Union. The results of their analysis reveal that despite the attempts to promote the integration of European energy markets through increased interconnection and market coupling price dispersion across Member States has been fully eliminated. Furthermore the increased penetration of generation technology from renewable sources in the last few years has affected the relationship between input (mainly coal and gas) prices and electricity prices, a relationship which was promoting price convergences across the different European markets. More specifically the empirical results of Gianfreda, Parisio and Pelagatti 
indicate that in recent year the influence of fuel prices on electricity prices has significantly diminished and that the increases RES-E penetration can be identified as one of the main causes on decreased levels of electricity market integration across the EU. They ascribe this phenomenon to overlapping national and supranational energy policies which produced conflicting results, such as the increased use of coal for electricity generation when this became cheaper than gas, despite the political and financial efforts aimed at promoting green generation and a reduction in GHG emissions.

\subsection{Issues Related to Transmission, Planning, Congestion and Pricing}

The next set of papers focuses on issues related to transmission planning, network pricing and congestion. Kemfert, Kunz and Rosellon (2016) focus on the effect of transmission planning on German electricity market. They highlight the role of the trade-off between transmission network development and generation dispatch, which has important welfare implications for investment decisions about expansion of the transmission network. As a result of their analysis they are bale to demonstrate that sub-optimal transmission planning, which does not account or the above-mentioned trade-off leads to excessive investment by the transmission system operator and to welfare reduction as a result of cost inflation. The analysis of the German case is particularly interesting as the energy policy in this country has promoted a significant expansion in electricity generation from renewable sources. This has created the need for expansion and reshaping of the electricity network, however transmission planning in Germany does not consider generation dispatch when determining the necessary investment in transmission expansion, as this is based on a congestionfree transmission network. It is the lack of a shadow value for congestion which leads to overinvestment as a result of profit maximisation choices by transmission system operators. Kemfert et al.'s analysis demonstrates that the optimal level of transmission expansion is achieved when the minimum level of congestion is coupled with minimum network cost. Their analysis allows them to evaluate the extent of overinvestment which is associated with the existing regulatory system. Indeed their analysis reveals investment costs at $45 \%$ above the optimal levels, as a result of the current cost-plus regulation of TSO's profitability, which does not account for generation dispatch and does not rely on nodal prices as signals for optimal generation location.

Optimal price zones also play an important role in determining social welfare as a result of energy policy interventions in the work of Grimm, Martin, Weibelzahl and Zottl (2016), who assess their potential impact on the liberalised European electricity markets. In investigating optimal zonal price configurations the authors highlight the importance of capacity constraints, which can limit the positive welfare effects of market splitting in the long run. While the introduction of optimal price zones can lead to investment in areas with low generation capacity in response to congestion issues, this method of addressing congestion can still give rise to overinvestment if technical and physical constraints limit the ability to use the transmission capacity, therefore 
leading to reductions in social welfare. The authors highlight the importance of distinguishing between short-run and long-run effects of increasing the number of price zones. They point out that in the short run this approach is always beneficial as it reduces re-dispatch costs, however it is important to consider the long-run effect of such policy as a result of the investment incentives it creates. Indeed once capacity adjustment is included in the analysis of the effect of zonal prices and increased refinement of price zones does not necessarily improve welfare. While the authors do not conclude that market splitting should always be considered undesirable, their analysis leads them to recommend that detailed consideration should be given to the development of price zones in European markets, taking into account the potential long run effects and investment incentives. This recommendation is particularly important for those countries with a level of interconnection with neighbouring countries.

\subsection{The European Natural Gas Market}

Two of the contributions to this special issue focus on the challenges currently faced in the European gas market. The gas industry has been for a long time the focus of concerns regarding security of supply in the European Union as a result of geopolitical uncertainty at the global level. Egging and Holz (2106) develop a stochastic model of the global natural gas market to evaluate investment decisions and trade flows in 3 long term scenarios associated with different types of risks: (i) potential disruptions of Russian supply (ii) demand changes due to gas intensity of electricity generation and (iii) availability of shale gas. Their analysis reveals how investment decisions are affected by economic agents' intertemporal hedging behaviour. The authors also find that developments in the global natural gas market are predominantly driven by demand-side pull factors (due to increasing gas intensity of power generation) rather than supply-side push factors (such as increased availability of shale gas). The results of their analysis lead the authors to reach some important conclusion about European policy for the gas market. Their scenario analysis supports additional reverse flow investment in Europe to mitigate the risk of supply disruptions form Russia and EU policies aimed at expanding the continent's LNG import capacity. Their results also confirm the importance of additional investment in pipelines such as the Southern Corridor project and the expanded interconnection of Poland with neighbouring countries, which are likely to generate welfare improvement subject to the efficient use of the European pipeline network, which can be achieved through the effective implementation of the European internal energy market.

Hulshof, van der Maat and Mulder (2016) also investigate the European gas market by assessing the role of market fundamentals as determinants of the recent evolution in natural gas prices. They provide empirical evidence in support of the view that recent EU policies have been successful in creating an efficient European gas market. On the one hand they recognise the beneficial effects of market liberalisation with the emergence of international gas hubs which promote gas to gas 
competition. On the other hand the authors express concerns about the fact that the market is still characterised by a limited number of suppliers and limited intensity of competition. Their analysis leads the authors to recommend that energy policies aimed at increasing gas to gas competition and increasing the level of integration across the European gas market should be extended, given the success achieved in promoting a liquid international spot market and reducing the influence of oil prices (through oil-linked long term contracts) on the process of price formation. These policies have relied not only on investment in cross border capacity and the elimination of trade barriers but also on an effective capacity allocation and congestion management mechanism.

\subsection{Sustainability and Reduced GHG Emissions}

Against the background of policies aimed at facilitating the development of integrated European markets for electricity and gas, one of the main drivers of European energy policy remains the pursuit of sustainability objectives, among which reductions in GHG emissions represents a dominant objective. The increased penetration of energy generation from renewable sources has created additional challenges in relation to the required adjustment to traditional market arrangements and the costs associated with them.

Pereira da Silva, Moreno and Figueiredo (2016) carry out an empirical assessment of the short-run and long-run effects of the prices of $\mathrm{CO}_{2}$ emissions on the stock market value of Spanish electricity firms. As discussed earlier the Spanish electricity market has been subject to radical transformations in their generation mix with high levels of penetration of generation from wind and solar power. Furthermore the EUETS is oldest and largest carbon market in the world and has been considered as an importance reference case for the development of other regimes so the analysis of this scheme can provide important lessons for policymakers in other parts of the world. The authors' analysis reveals that the stock market impact of variations in emission prices is different depending on the EU-ETS phase under consideration and on the firm's generation mix. They also find out that stock market effect can be asymmetric, i.e. the size of the effect is different for positive and negative changes in emission prices. More specifically in phase II of EU-ETS they observe positive long run effects of emissions price variation, with firm specific asymmetric effects. On the contrary they do not observe any significant long-run effects in Phase III. Furthermore while the effects is phase II affect mostly firms with a fuel mix dominated by fossil fuel, only firms with a prevalence of generation from renewable sources see a significant impact on their stock market variation. The authors argue that the differences between the two phases should be ascribed to difference in the initial allowance allocation which has initially favoured fossil fuel generators. The results of this work lead to the conclusion that policymakers should be aware of the potential stock market implications for companies with different generation mixes when devising market design and allowance allocation for the emission trading schemes being implemented across the world. 
Böhringer, Bortolamedi, Keller and Seyffarth (2016) highlight the complex nature of the current European Union's emissions control and energy policies, which are underpinned by the need for Government intervention in markets in response to the market failures associated with climate protection. Several decades of leadership in the global climate action have produced a series of overlapping, and at times conflicting, objectives and instruments which might hinder effective action on energy and climate, and might result in unnecessary costs being borne by society. In order to evaluate the extent of these problems the authors carried out a rigorous impact assessment of the EU climate and energy policy to examine their effectiveness and associated costs. They identify cost-related problems with the implementation of the EU-ETS, which covers only energy-intensive industry, while emissions abatement for other economic sectors is pursued through national regulation. The lack of formal linkages between ETS and non-ETS sectors of the economies hinders the achievement of emission reductions by equalising marginal abatement costs across markets, thus increasing the total cos of abatement. Further sources of excess costs are represented by the implementation of policies which support the development of renewable technologies and energy efficiency measures which are not explicitly coordinated with the emission trading scheme. The authors' analysis reveals that regulations on energy efficiency improvements cause a costly deviation from the cost-effective abatement patterns which could be achieved by relying stand-alone pricing schemes only. They argue that this lacks of cost-effectiveness in EU climate and emission abatements policies weaken the potential leading role of the European Union in promoting economically viable decarbonisation policies which could be adopted in less wealthy areas of the world.

\section{Acknowledgements}

The editors would like to thank all those involved in the "International Academic Symposium on Energy Markets and Sustainability" held February 3rd 2015, in Barcelona, Spain. Special thanks are due to the event's keynote speaker David Newbery (Cambridge University) and to chair discussants Ronald Huisman (Erasmus University Rotterdam), Alessandro Costa (World Energy Council) and Paulina Beato (Economic Adviser). All the papers in this special issue have been subject to a blind review process, involving at least two reviewers. The contribution of the reviewers with their valuable comments and suggestion contributed to improve the quality of the papers contained in this special issue so we would like to thank all of them for the time and effort devoted to the process. We would also like to thank the Energy Policy editor Stephen P. A. Brown for his support during the review, production and publication processes. We are also grateful for the generous support of the Chair of Energy Sustainability (Barcelona Institute of Economics, University of Barcelona), the Generalidad de Catalunya SGR project 2015-SGR-531, the Ministerio de Economía y Competitividad project ECO2015-69107-R, and the sponsorship of FUNSEAM (Energy and Environment Sustainability Foundation). Monica Giulietti acknowledges financial support from EPSRC (IMAGES project, 
number EP/K002228/1, and CMADEnS project, number EP/N001745/1). The authors are solely responsible for the views expressed here, as well as all errors and omissions.

\section{Disclaimer}

Monica Giulietti is member of the Panel of Technical of Technical Experts advising UK Department of Energy and Climate Change on the delivery of Electricity Market Reform, but has written this article in her academic capacity and relying only on publicly available information.

\section{References}

Batalla-Bejerano, J., Costa-Campi, MT. and E. Trujillo-Baute, 2016. Collateral effects of liberalisation: Metering, losses, load profiles and loss settlements in Spain's electricity system. Energy Policy, XX XXX-XX.

Batalla-Bejerano, J. and E. Trujillo-Baute, 2016. Impacts of intermittent renewable generation on electricity system costs. Energy Policy, XX XXX-XX.

Böhringer,C., Bortolamedi, M., Keller A. and A. Rahmeier Seyffarth , 2016. Good things do not always come in threes: On the excess cost of overlapping regulation in EU climate policy. Energy Policy, XX XXX-XX.

De Hautecloque, A., 2009. Legal ncertainty and competition policy in European deregulated electricity markets: the case of long term exclusive supply contracts. World Competition, Law and Economics Review, 32(1), 91-112.

Egging, R. and F.Holz, 2016. Risks in global natural gas markets: investment, hedging and trade. Energy Policy, XX XXX-XX.

European Commission, 2015, Energy Union Package. A Framework Strategy for a Resilient Energy Union with a Forward-looking Climate Change Policy, Brussels, $\operatorname{COM}(2015) 80$ final (accessed 01.03.2015)

Gianfreda, A., Parisio, L. and M. Pelagatti, 2016. Revisiitng long-run relations in power markets with high RES penetration. Energy Policy, XX XXX-XX.

Grimm, V., Martin, A., Weibelzahl, M. and G. Zottl, 2016. On the long-run effects of market splitting: why more price zones might decrease welfare. Energy Policy, $X X$ XXX-XX.

Helm, D., 2014. The European framework for energy and climate policies. Energy Policy 64, 29-35. 
Henriot, A. and JM Glachant, 2013. Melting pots and salad bowls: the current debate of electricity market design for integration of intermittent RES, Utilities Policy, 27, 5764.

Huber, M., Dimkova, D. and T.Hamaker, 2014. Integration of wind and solar power in Europe; assessment of flexibility requirements. Energy 69, 236-246.

Hulshorf, D., JP., van der Maat and M. Mulden, 2016. Market fundamentals, competition and natural gas prices. Energy Policy, XX XXX-XX.

Kemfert, C., Kunz, F. and J. Rosellon, 2016. A welfare analysis of the electricity transmission regulatory regime in Germany. Energy Policy, XX XXX-XX.

Marty, F., 2016. L'Europe de l' energie: de la concurrence 'a la solidarite? Hal archives ouvertes working paper halshs- 01273770.

Motta, M. (2004), Competition policy: Theory and Practice, Cambridge University Press.

Newbery, D., 2016. Missing money and missing markets: Reliability, capacity auctions and interconnectors. Energy Policy, XX XXX-XX.

Pereira da Silva, P., Moreno, B. and N. Figueiredo, 2016. Carbon emission prices and stock market returns of Spanish power industry: Does this interaction work asymmetrically? Energy Policy, XX XXX-XX.

Westphal, K., 2014.Institutional change in European natural gas markets and implications for energy security: lessons from the German case. Energy Policy, 74, 35-43.

\section{M.T.Costa-Campi}

Department of Public Economics, University of Barcelona and Chair of Energy Sustainability, Barcelona Institute of Economics (IEB)

E-mail address: mtcosta@ub.edu

\section{Giulietti}

School of Business and Economics, University of Loughborough

E-mail address: M.Giulietti@lboro.ac.uk

\section{E. Trujillo-Baute}

Department of Economics, University of Warwick and Chair of Energy Sustainability, Barcelona Institute of Economics (IEB) E-mail address: e.trujillo-baute@warwick.ac.uk 